Document downloaded from:

http://hdl.handle.net/10251/65503

This paper must be cited as:

Kasper, AC.; Carrillo Abad, J.; García Gabaldón, M.; Veit, HM.; Pérez-Herranz, V. (2015). Determination of the potential gold electrowinning from an amoniacal thiosulphate solution applied to recycling of printed circuit board scraps. Waste Management and Research. 34(1):47-57. doi:10.1177/0734242X15607425.

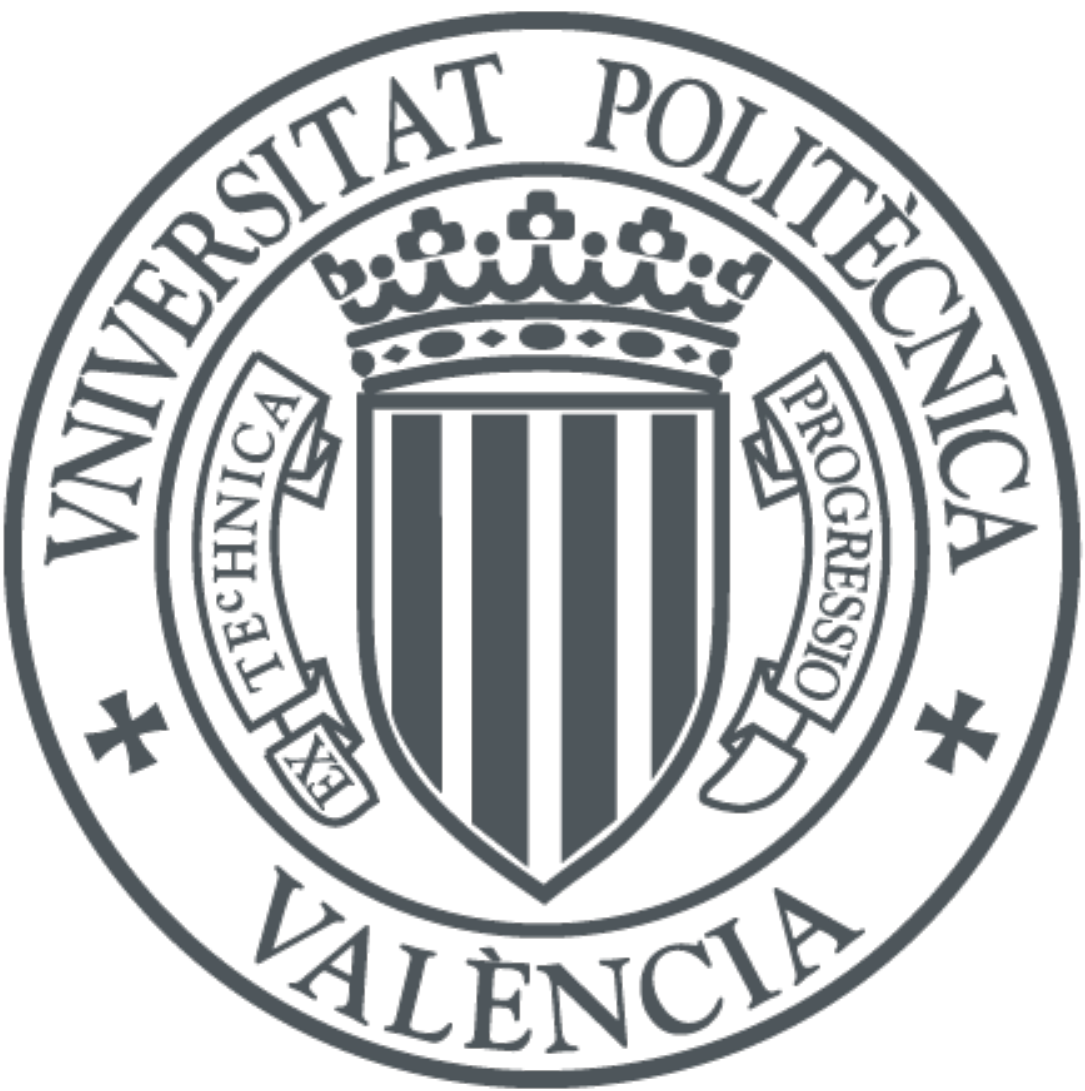

The final publication is available at

http://dx.doi.org/10.1177/0734242X15607425

Copyright SAGE Publications

Additional Information 


\title{
Determination of the potential gold electrowinning from an ammoniacal thiosulphate solution applied to recycling of printed circuit board scraps
}

\author{
Angela C Kasper ${ }^{1}$, Jordi Carrillo Abad ${ }^{2}$, Montserrat García Gabaldón², Hugo M Veit ${ }^{1}$ \\ and Valentín Pérez Herranz ${ }^{2}$
}

\author{
1LACOR-PPGE3M, Universidade Federal do Rio Grande do Sul, Rio Grande do Sul, \\ Brazil \\ 2Departamento de Ingeniería Química y Nuclear, Universidad Politécnica de \\ Valencia, Valencia, Spain
}

Corresponding author:

Angela C Kasper, LACOR-PPGE3M, Universidade Federal do Rio Grande do Sul, Av. Bento Gonçalves, 9500, Setor 4, Prédio 43426, 91501-970 - Porto Alegre, Rio Grande do Sul, Brazil. Email: angelakasper@globo.com

\begin{abstract}
.
The use of electrochemical techniques in the selective recovery of gold from a solution containing thiosulphate, ammonia, and copper, obtained from the leaching of printed circuit boards from mobile phones using ammoniacal thiosulphate, are shown in this work. First, cyclic voltammetry tests were performed to determine the potential of electrodeposition of gold and copper, and then, electrowinning tests at different potentials for checking the rates of recovery of these metals were performed. The results of the cyclic voltammetry show that copper deposition occurs at potentials more negative than $-600 \mathrm{mV}(\mathrm{Ag} / \mathrm{AgCl})$, whereas the gold deposition can be performed at potentials more positives than $-600 \mathrm{mV}(\mathrm{Ag} / \mathrm{AgCl})$. The results of electrowinning show that $99 \%$ of the gold present in solutions containing thiosulphate and copper can be selectively recovered in a potential range between $-400 \mathrm{mV}(\mathrm{vs} \mathrm{Ag} / \mathrm{AgCl}$ ) and $-500 \mathrm{mV}$ (vs $\mathrm{Ag} / \mathrm{AgCl}$ ). Furthermore, 99\% of copper can be recovered in potentials more negative than $-700 \mathrm{mV}$ (vs Ag/ $\mathrm{AgCl})$.
\end{abstract}

\section{Keywords.}

Printed circuit boards, gold, thiosulphate, cyclic voltammetry, electrolysis studies, gold electrowinning 


\section{Introduction.}

Technological developments observed in recent years have made electrical and electronic equipment extremely popular, which has brought up environmental problems, such as the increase on demand for precious metals and the disposal and/or discard of the electronic appliance, that become obsolete very rapidly. An alternative to minimise this problem would be the recovery of metals, like gold, from the discarded electronic scraps.

Gold, owing to its characteristics, combines excellent conductivity with high corrosion resistance, and it is widely used in industries for electrical and electronic products. It can be found in printed circuit boards of computers, mobile phones, smart phones, televisions, and cameras, among other products. Thus, when these electrical and electronic products are discarded by technological obsolescence or defects, without adequate treatment, significant quantities of gold and other metals are wasted (Babu et al., 2007; Chancerel et al., 2010). A tonne of printed circuit boards of mobile phones, for example, contains on average about $340 \mathrm{~g}$ of gold. Considering that each year thousands of devices of mobile phones, obsolete or defective, are discarded worldwide, the value of the gold in the market, and the reduction of its natural reserves, it can be promising that their recycling is beneficial for both economic and environmental aspects (Friege, 2012; Hagelüken and Corti, 2010; Kasper et al., 2011a).

An alternative for the recovery of gold present in the printed circuit boards of mobile phones would be to use a combination of hydrometallurgical techniques (metal dissolution) and electrometallurgical techniques (metal recovery).

In the conventional processes for gold recovery by the hydrometallurgical route, products based on cyanide could be used to extract the gold present in electronic scrap. However, the cyanide is highly toxic and, therefore, should be handled and disposed of into the environment with care and with proper treatment. In view of this, other products with lower environmental impacts have been tested. Among these alternative leaching agents, the thiosulphate is one of the greater possibilities of industrial application (Aylmore, 2005; Zhang et al., 2012).

The use of thiosulphate in the leaching of gold ores has been widely studied. These studies show that the efficiency of thiosulphate as a leaching agent depends on the type of mineral to which gold is associated. The results indicated that for some types of gold ores, the leaching rates were better than those obtained in the conventional cyanidation; whereas for other types of gold ores, the leaching rates were deemed unsatisfactory (Arslan and Sayiner, 2008; Aylmore and Muir, 2001; Berezowsky and Sefton, 1979; Feng and Van Deventer, 2006, 2007; Navarro et al., 2002; Senanayake, 2007). The thiosulphate was also tested with success as a leaching agent for gold in the scrap of printed circuit boards of mobile phones (Ha et al., 2010; Tripathi et al., 2012).

The gold leaching process by thiosulphate may be described by the following reaction (Abbruzzese et al., 1995): 


$$
\mathrm{Au}+5 \mathrm{~S}_{2} \mathrm{O}_{3}^{2-}+\mathrm{Cu}\left(\mathrm{NH}_{3}\right)_{4}^{2+} \leftrightarrow \mathrm{Au}\left(\mathrm{S}_{2} \mathrm{O}_{3}\right)_{2}^{3-}+\mathrm{Cu}\left(\mathrm{S}_{2} \mathrm{O}_{3}\right)_{3}^{5-}+4 \mathrm{NH}_{3}
$$

The dissolution of gold by thiosulphate takes place by the formation of a complex aurothiosulphate $\left[\mathrm{Au}\left(\mathrm{S}_{2} \mathrm{O}_{3}\right)_{2}{ }^{3-}\right]$. In addition to thiosulphate, in this process, copper (II) sulphate and ammonium are used. Copper (II) sulphate acts as an oxidising agent, catalyzing the reaction. The ammonium has the role of stabilising copper II, through the formation of a cupric tetraamine complex $\left[\mathrm{Cu}\left(\mathrm{NH}_{3}\right)_{4}{ }^{2+}\right]$ (Aylmore and Muir, 2001; Breuer and Jeffrey, 2000; Jeffrey, 2001; Li et al., 1995; Senanayake, 2004; Zhang and Nicol, 2003, 2005).

The recovery of gold from conventional cyanide leach liquors has been performed using several techniques, such as electrowinning, precipitation, solvent extraction, activated charcoal, and ion exchange resin. Similarly, these same processes have also been be applied to the recovery of gold from ammoniacal thiosulphate leach liquors (Grosse et al., 2003).

The electrowinning is an electrochemical process of the recovery of metal ions from solution by the application of different potentials or current intensities. In this process, the ions in the solution will migrate to the cathode and form a metallic deposit. The electrowinning is employed to extract metals, such as cop- per, zinc, nickel, gold, manganese, and cadmium, from their solutions, and various studies indicate that it is an process attractive both economically and environmentally (Carrillo-Abad et al., 2012; Fourcade et al., 2003; Garcia-Gabaldon et al., 2005; Garcia-Gabaldon et al., 2006; Gromov et al., 2004; Kasper et al., 2011b; Peng et al., 2011; Reyes Cruz et al., 2002; Veit et al., 2006; Yap and Mohamed, 2007).

However, researches regarding the recovery of gold from ammoniacal thiosulphate solution by electrowinning show con- troversial results. Some authors consider this technique feasible while others disagree. The high copper concentration and reactions involving oxidation or reduction of thiosulphate are considered the main barriers for the gold recovery by electrochemical techniques (Alonso et al., 2007; Aylmore, 2005; Aylmore and Muir, 2001; Grosse et al., 2003; Harrison and Thompson, 1973; Trindade and Barbosa Filho, 2002).

Thus, according to these controversial results reported by several authors, this article aims to study of the reduction potentials to gold and copper in solutions containing thiosulphate and, from this, verify the possibility of gold recovery from printed circuit boards of mobile phones by electrowinning. 


\section{Materials and methods.}

Initially, some considerations should be made regarding the materials used in this study.

1. The anion $\left[\mathrm{AuCl}_{4}{ }^{-}\right]$is used to prepare gold complexes. In solution, this anion can suffer acid or alkaline hydrolysis, where the chloride ions are replaced by $\left[\mathrm{H}_{2} \mathrm{O}\right]$ or [ $\left.\mathrm{OH}^{-}\right]$, respectively (Mironov and Makotchenko, 2009).

2. The potential of gold electrowinning is affected by several factors, such as the nature of the electrode, $\mathrm{pH}$, complexing agents, electrolytes, and other metal ions present in the solution (Trejo et al., 1996).

3. The gold in ammoniacal medium can dissociate, forming gold (III) and gold (I) (Lack et al., 1999).

\section{Solutions}

In this work, the following reagents were used: Gold (III) chloride $\left(\mathrm{AuCl}_{3}, 64.4 \% \mathrm{Au}\right.$, by Alfa Aesar $\mathrm{GmbH}$ ), copper (II) sulphate $\left(\mathrm{CuSO}_{4} .5 \mathrm{H}_{2} \mathrm{O}\right.$, by Panreac), sodium thiosulphate $\left(\mathrm{Na}_{2} \mathrm{~S}_{2} \mathrm{O}_{3} \cdot 5 \mathrm{H}_{2} \mathrm{O}\right.$, by Panreac), ammonium hydroxide $\left(\mathrm{NH}_{4} \mathrm{OH}, 29 \%\right.$, by J T Baker), sodium hydroxide ( $\mathrm{NaOH}$, by Panreac), and hydrochloric acid ( $\mathrm{HCl}$ by Panreac).

A synthetic solution containing $1000 \mathrm{ppm}$ of gold was prepared by dissolving the gold (III) chloride in water and hydrochloric acid, forming $\mathrm{HAuCl}_{4}$. Aliquots were removed from this solution for testing cyclic voltammetry and electrolysis.

In the cyclic voltammetry studies, solutions obtained in previous studies (Ha et al., 2010; Kasper et al. 2012; Tripathi et al., 2012), containing $0.12 \mathrm{M}$ thiosulphate, $15 \mathrm{mM}$ copper sulphate, and $0.2 \mathrm{M}$ ammonia were used. For the electrolysis studies, $1000 \mathrm{ppm}$ (1000 $\mathrm{mg} \mathrm{Cu} \mathrm{L}^{-1}$ ) of copper was used, whereas the concentrations of sodium thiosulphate and ammonia were the same used in the cyclic voltammetry studies.

The thiosulphate and copper solutions were prepared before each test. All solutions were obtained from analytical grade reagents and prepared with distillated water.

All the studies were performed at $\mathrm{pH} 10 \pm 0.1$ and a temperature of $25 \pm 1^{\circ} \mathrm{C}$.

\section{Voltammetry studies}

In this study, a conventional three-electrode cell was used. A platinum rotating disc enclosed in Teflon with a surface area of $0.078 \mathrm{~cm}^{2}$ was used as a working electrode. An electrode of $\mathrm{Ag} / \mathrm{AgCl}$ (in saturated $\mathrm{KCl}$ ) was used as the reference electrode, and a platinum electrode was used as the counter electrode.

Before each experiment, the surface of the working electrode was mechanically polished (with use of alumina powder) and rinsed off with distilled water. The solutions were deoxygenated for 10 minutes with ultrapure nitrogen. The atmosphere was maintained inert during the whole measurement to eliminate oxygen reduction as a 
cathodic reaction.

The electrolytes used in this work, to cyclic voltammetry studies, are shown in Table 1.

The potential range used in this study was $+1500 \mathrm{mV}$ to $-1500 \mathrm{mV}$. The electrochemical experiments were controlled using an Autolab PGSTAT20 potentiostat/galvanostat connected to a PC (Software GPES 4.9).

Table 1. List of cyclic voltammetry tests shown in this article.

\begin{tabular}{lll}
\hline Voltammetry & Electrolytes & Figure \\
\hline 1 & $\mathrm{Cu}+\mathrm{Na}_{2} \mathrm{~S}_{2} \mathrm{O}_{3}+\mathrm{NH}_{4} \mathrm{OH}$ & 1 \\
2 & $\mathrm{Cu}+\mathrm{NH}_{4} \mathrm{OH}$ & \\
3 & $\mathrm{Au}(50 \mathrm{ppm})+\mathrm{NH}_{4} \mathrm{OH}$ & 2 \\
4 & $\mathrm{Au}(100$ ppm $)+\mathrm{NH}_{4} \mathrm{OH}$ & \\
5 & $\mathrm{Au}(100 \mathrm{ppm})+\mathrm{Na}_{2} \mathrm{~S}_{2} \mathrm{O}_{3}+\mathrm{NH}_{4} \mathrm{OH}$ & 3 \\
6 & $\mathrm{Au}(100 \mathrm{ppm})+\mathrm{NH}_{4} \mathrm{OH}$ & \\
7 & $\mathrm{Cu}+\mathrm{Na}_{2} \mathrm{~S}_{2} \mathrm{O}_{3}+\mathrm{NH}_{4} \mathrm{OH}$ & 4 \\
8 & $\mathrm{Au}+\mathrm{Cu}+\mathrm{Na}_{2} \mathrm{~S}_{2} \mathrm{O}_{3}+\mathrm{NH}_{4} \mathrm{OH}$ &
\end{tabular}

\section{Electrolysis studies}

The electrochemical reactor used in this work consisted of a $150 \mathrm{~mL}$ Pyrex glass. Two electrodes of graphite were used with the cathode and the anode, and an electrode of $\mathrm{Ag} / \mathrm{AgCl}$ (in saturated $\mathrm{KCl}$ ) was used with the reference electrode. Both the cathode and the anode were made of two cylindrical graphite bars with an effective area of 14.15 $\mathrm{cm}^{2}$.

Preliminary leaching tests carried out by the authors (Kasper et al., 2011b) and the literature data (Chancerel et al., 2009; Huisman, 2008; UNEP, 2009, 2013) show that the amount of gold present in the printed circuit boards of mobile phones is variable depending on the type or model of board. Consequently, the amount of gold present in the leaching solution also can vary. Therefore, in this work, electrowinning tests were performed, initially with solutions containing $100 \mathrm{ppm}$ of gold, and after with solutions containing $10 \mathrm{ppm}$ of gold. In both cases, the concentrations of the other components present in the solution (copper, ammonia, and thiosulphate) were kept constant.

The electrowinning tests performed in this work are shown in Table 2.

The electrolysis experiments were controlled with a potentiostat/galvanostat Autolab PGSTAT302N that was connected to a PC (Software GPES 4.9).

The gold and copper concentrations in solutions were measured by atomic absorption spectrophotometry (AAS) with Spectrophotometer Perkin-Elmer, model Analyst 100. For measuring the concentration of gold, a gold hollow cathode lamp at $242.8 \mathrm{~nm}$ wavelength, $0.2 \mathrm{~nm}$ spectral bandwidth, and an operating current of $10 \mathrm{~mA}$ was used. For measuring the concentration of the copper hollow lamp, the wavelength used was $218.2 \mathrm{~nm}$, the spectral bandwidth was $0.2 \mathrm{~nm}$, and the applied operating current was 
$10 \mathrm{~mA}$.

Table 2. List of electrowinning tests performed in this article.

\begin{tabular}{llll}
\hline Electrolysis & Solution composition & Potential $(\mathrm{mV})$ & Figure \\
\hline Gold electrowinning & $\mathrm{Au}(100 \mathrm{ppm})+\mathrm{Cu}+\mathrm{Na}_{2} \mathrm{~S}_{2} \mathrm{O}_{3}+\mathrm{NH}_{4} \mathrm{OH}$ & -250 & 5 \\
& & -400 & -500 \\
& & -700 & -1000 \\
Copper electrowinning & $\mathrm{Au}(100 \mathrm{ppm})+\mathrm{Cu}+\mathrm{Na}_{2} \mathrm{~S}_{2} \mathrm{O}_{3}+\mathrm{NH}_{4} \mathrm{OH}$ & -500 & 6 \\
& & -700 & 11 \\
Gold electrowinning & $\mathrm{Au}(10 \mathrm{ppm})+\mathrm{Cu}+\mathrm{Na}_{2} \mathrm{~S}_{2} \mathrm{O}_{3}+\mathrm{NH}_{4} \mathrm{OH}$ & -1000 & -500 \\
\end{tabular}




\section{Results and discussion.}

The use of electrochemical processes in the selective recovery of metals from a solution depends on the electrodeposition potential of each of these metals. Thus, if the electrodeposition potentials are very different, it is possible to easily recover these metals by performing successive stages of electrowinning at different potentials. In the case of gold and copper, these potentials are fairly close, which requires a strict control of the system variables, in order to obtain a selective and efficient recovery between the two species.

\section{Voltammetry study of copper.}

Figure 1 shows a comparison between voltammograms obtained in tests with copper sulphate with and without thiosulphate. In Figure 1 we can see two peaks of reduction in the voltammogram from the solution without thiosulphate, peak $A$ at approximately $-450 \mathrm{mV}$ (vs $\mathrm{Ag} / \mathrm{AgCl}$ ) and peak $\mathrm{B}$ at approximately $-150 \mathrm{mV}$ (vs $\mathrm{Ag} / \mathrm{AgCl}$ ). In the voltammogram, the solution containing thiosulphate only one peak of the reduction, peak $\mathrm{C}$ at approximately $-600 \mathrm{mV}(\mathrm{vs} \mathrm{Ag} / \mathrm{AgCl})$ was detected.

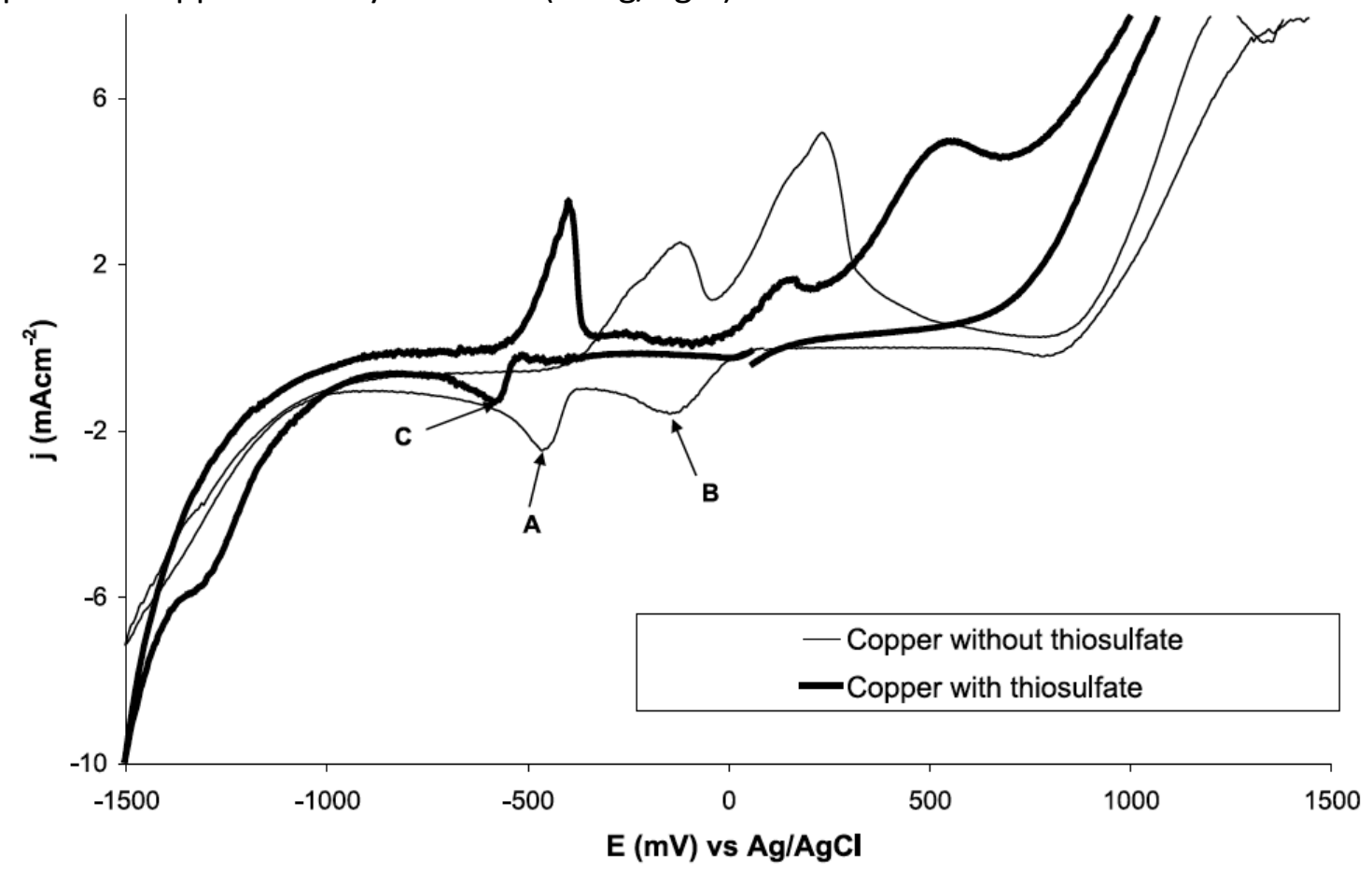

Figure 1. Cyclic voltammograms obtained at a platinum electrode of $15 \mathrm{mM} \mathrm{CuSO}_{4}, 0.2$ $\mathrm{M}$ de $\mathrm{NH}_{4} \mathrm{OH}$, and $0.12 \mathrm{M} \mathrm{Na}_{2} \mathrm{~S}_{2} \mathrm{O}_{3} ; \mathrm{pH} 10( \pm 0.1)$; Scan rate $20 \mathrm{mVs}^{-1}$.

This behaviour can be explained by the fact that the copper, in the aqueous solutions, reacts with ammonium and forms two highly stable complexes: the cupric ammine complex $\left[\mathrm{Cu}\left(\mathrm{NH}_{3}\right)_{4}{ }^{2+}, \mathrm{Cu}\left(\mathrm{NH}_{3}\right)_{5}{ }^{2+}, \mathrm{Cu}\left(\mathrm{NH}_{3}\right)_{3}{ }^{2+}\right]$ and the cuprous ammine complex $\left[\mathrm{Cu}\left(\mathrm{NH}_{3}\right)_{2}{ }^{+}\right.$]. Peak $\mathrm{A}$ at $-450 \mathrm{mV}$ (vs Ag/AgCl) corresponds to a reduction of $\mathrm{Cu}(\mathrm{II}) / \mathrm{Cu}(\mathrm{I})$, whereas peak $\mathrm{B}$ at $-150 \mathrm{mV}(\mathrm{vs} \mathrm{Ag} / \mathrm{AgCl}$ ) corresponds to a reduction of $\mathrm{Cu}(\mathrm{I}) / \mathrm{Cu}(0)$. These results are similar to the results obtained by other researchers in studies on the electrochemical behaviour of copper/ammonium solutions (Giannopoulou et al., 2009; Koyama et al., 2006; Vazquez-Arenas et al. 2007). 
With the addition of thiosulphate to the solution containing copper, the concentration of $\mathrm{Cu}$ (II) decreases in an ammoniacal medium. This decreases the concentration of $\mathrm{Cu}(\mathrm{II})$, especially in the absence of oxygen owing to the reaction of copper with thiosulphate. This fact indicates that the copper solution with thiosulphate reacts and forms the complex $\mathrm{Cu}(\mathrm{I})$, which means that under these conditions, electrodeposition occurs in one step. Therefore, we observe only a single peak of reduction, peak $C$, in approximately $-600 \mathrm{mV}$ (vs $\mathrm{Ag} / \mathrm{AgCl}$ ), which corresponds to a reduction of $\mathrm{Cu}(\mathrm{I}) / \mathrm{Cu}(0)$.

\section{Voltammetry study of gold}

Figure 2 shows a comparison between the cyclic voltammograms obtained from tests on two different concentrations of gold in ammoniacal medium (at $50 \mathrm{ppm}$ and at 100 $\mathrm{ppm})$ at $\mathrm{pH} 10( \pm 0.1)$. In this voltammogram, two peaks of cathodic reduction are observed, whose intensity increases with the increase of the concentration of gold in the solution. This fact indicates that these two peaks refer to gold reduction processes.

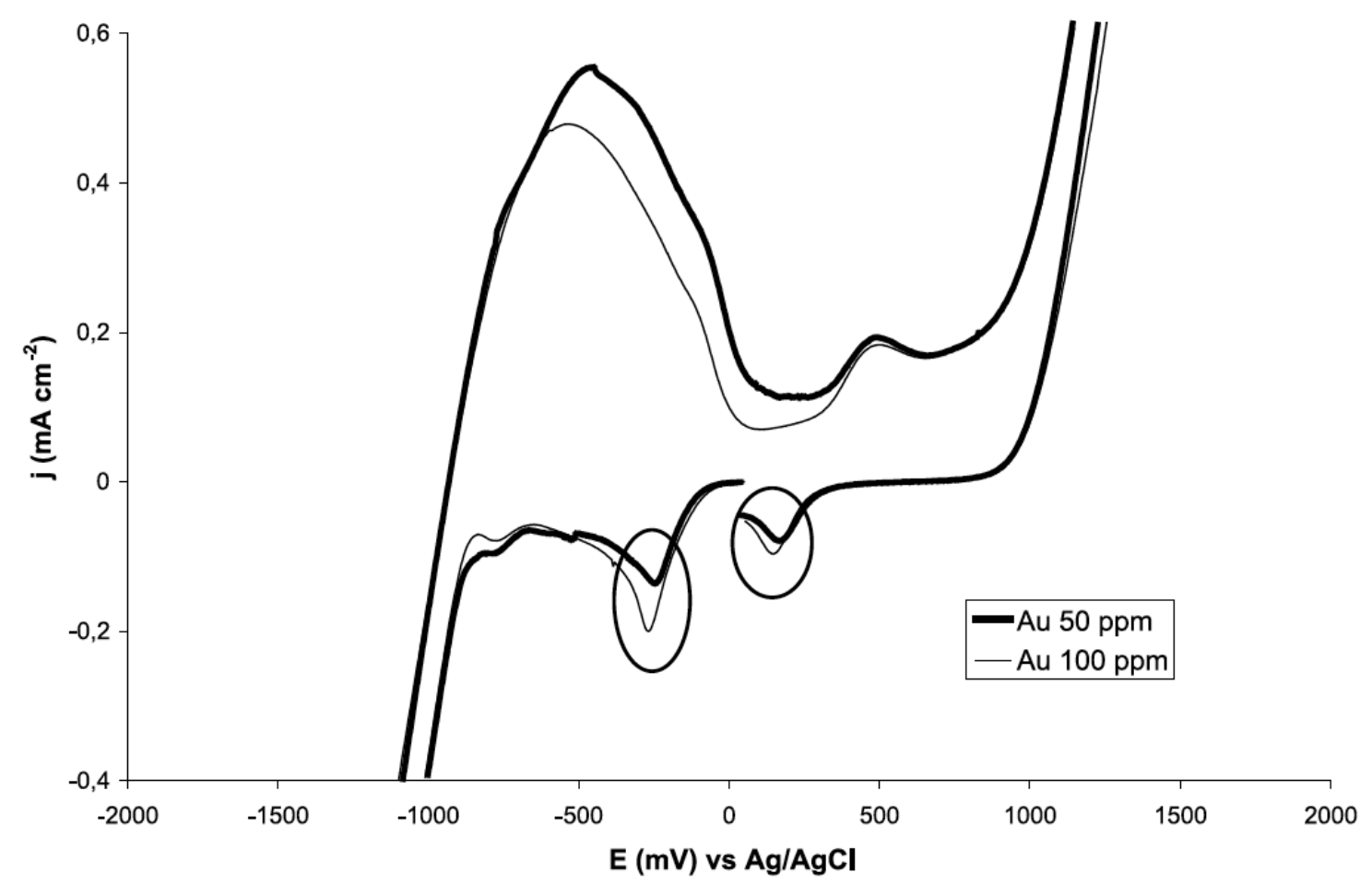

Figure 2. Cyclic voltammograms of gold in ammoniacal medium at a platinum electrode; $\mathrm{pH} 10$ ( \pm 0.1$)$; Scan rate $20 \mathrm{mVs}^{-1}$.

Thus, the peak at approximately $150 \mathrm{mV}$ (vs $\mathrm{Ag} / \mathrm{AgCl}$ ) corresponds to the reduction of $\mathrm{Au}(\mathrm{III}) / \mathrm{Au}(\mathrm{I})$, and another peak at approximately $-230 \mathrm{mV}$ (vs $\mathrm{Ag} / \mathrm{AgCl}$ ) corresponds to the reduction of $\mathrm{Au}(\mathrm{I}) / \mathrm{Au}(0)$.

Figure 3 shows a comparison between the cyclic voltammograms obtained in the tests with solutions containing gold, with and without thiosulphate, in an ammoniacal medium. 


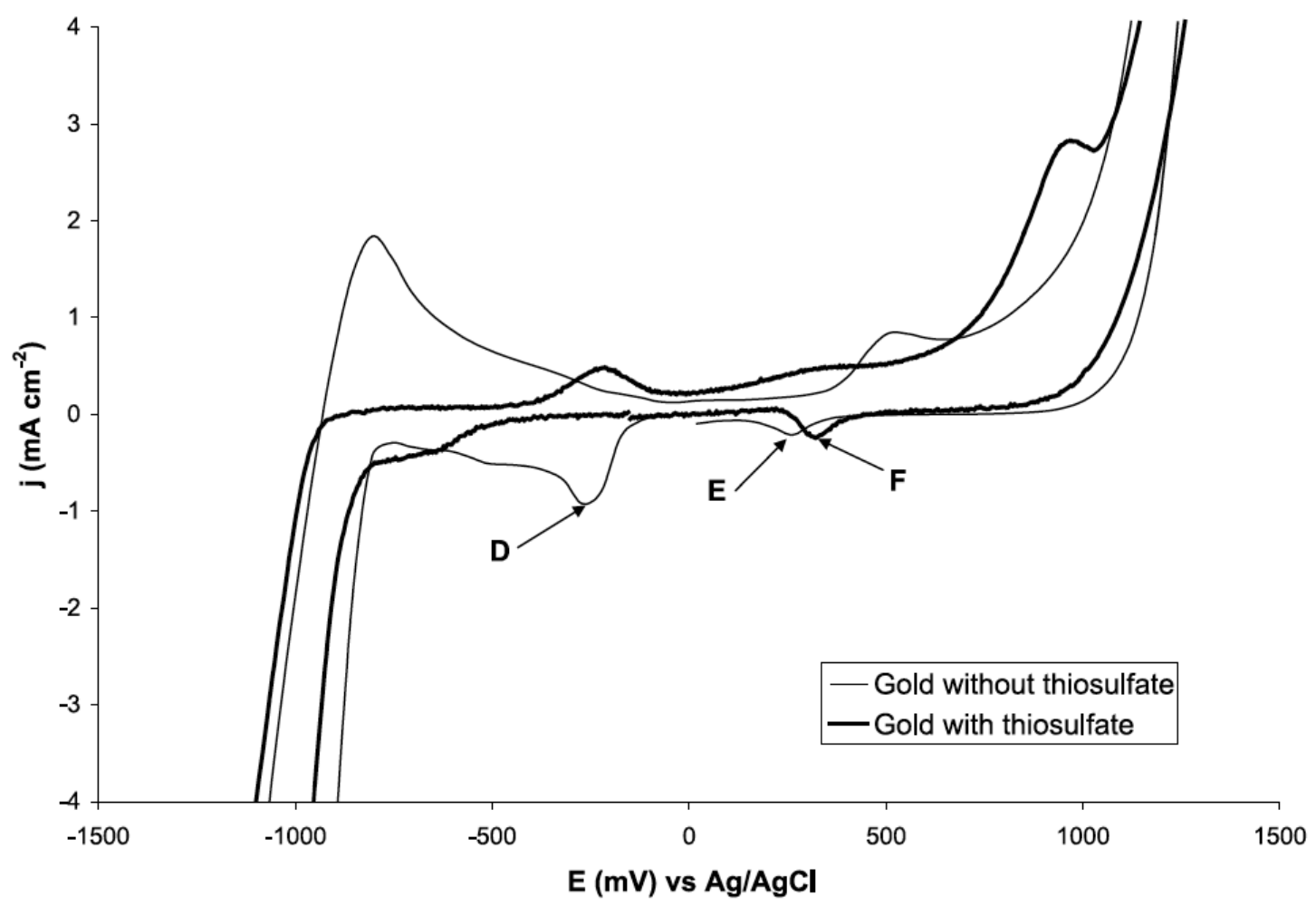

Figure 3. Cyclic voltammograms obtained at a platinum electrode by $500 \mathrm{ppm} \mathrm{Au}, 0.2 \mathrm{M}$ de $\mathrm{NH}_{4} \mathrm{OH}$, and $0.12 \mathrm{M} \mathrm{Na}_{2} \mathrm{~S}_{2} \mathrm{O}_{3}$; Scan rate $60 \mathrm{mVs}^{-1}$.

The order of stability constant $(\log \beta)$ is $\left[\mathrm{Au}\left(\mathrm{S}_{2} \mathrm{O}_{3}\right)_{2}{ }^{3-}\right]>\left[\mathrm{Au}\left(\mathrm{NH}_{3}\right)^{+2}\right]>\left[\mathrm{AuCl}_{2}\right]$, with the value of 26, 19 and 9, respectively. Thus, the gold(I) complex formed with thiosulphate predominates over the other complexes. This was evidenced by the fact that, during the preparation of solutions for the tests, the solution of gold chloride (III) with the yellow colour became colourless from the addition of thiosulphate, indicating the formation of an aurothiosulphate complex.

This comparison shows two peaks of cathodic reduction, peak $\mathrm{D}$ at $-250 \mathrm{mV}(\mathrm{vs} \mathrm{Ag} / \mathrm{AgCl})$ and peak $\mathrm{E}$ at $250 \mathrm{mV}$ (vs $\mathrm{Ag} / \mathrm{AgCl}$ ) for a solution containing only gold (an ammoniacal medium); these peaks correspond to a reduction of $\mathrm{Au}(\mathrm{III}) / \mathrm{Au}(\mathrm{I})$ and a reduction of $\mathrm{Au}(\mathrm{I}) / \mathrm{Au}(0)$. However, when the thiosulphate is added to the solution, only one peak of the cathodic reduction is observed, peak $\mathrm{F}$ in approximately $300 \mathrm{mV}(\mathrm{vs} \mathrm{Ag} / \mathrm{AgCl})$; this peak corresponds to the reduction of $\mathrm{Au}(\mathrm{I}) / \mathrm{Au}(0)$.

\section{Voltammetric study of gold-copper-thiosulphate-ammonium solutions}

Figure 4 shows a comparison between a solution of thiosulphate in an ammoniacal medium containing only copper and a solution of thiosulphate in an ammoniacal medium containing copper and gold.

In the voltammogram obtained from the solution containing copper and gold, two reduction peaks are observed. The first peak, peak $\mathrm{G}$, at approximately $-630 \mathrm{mV}$ (vs $\mathrm{Ag} / \mathrm{AgCl}$ ), corresponds to the reduction of $\mathrm{Cu}(\mathrm{I}) / \mathrm{Cu}(0)$, and the second peak, peak $\mathrm{H}$, corresponds to the peak reduction of $A u(I) / A u(0)$, which now appears shifted in the positive direction by about $-50 \mathrm{mV}$. In the voltammogram obtained of a solution 
containing thiosulfate and copper, the peak I corresponds to the reduction of $\mathrm{Cu}(\mathrm{I}) / \mathrm{Cu}(0)$ in approximately $-600 \mathrm{mV}(\mathrm{vs} \mathrm{Ag} / \mathrm{AgCl})$, and which in the presence of gold was shifted in the negative direction.

The fact that the peaks of reduction of the copper (peak G) and the gold (peak H) appear clearly separated indicates that under these conditions, selective electrodeposition of the two metals would be possible.

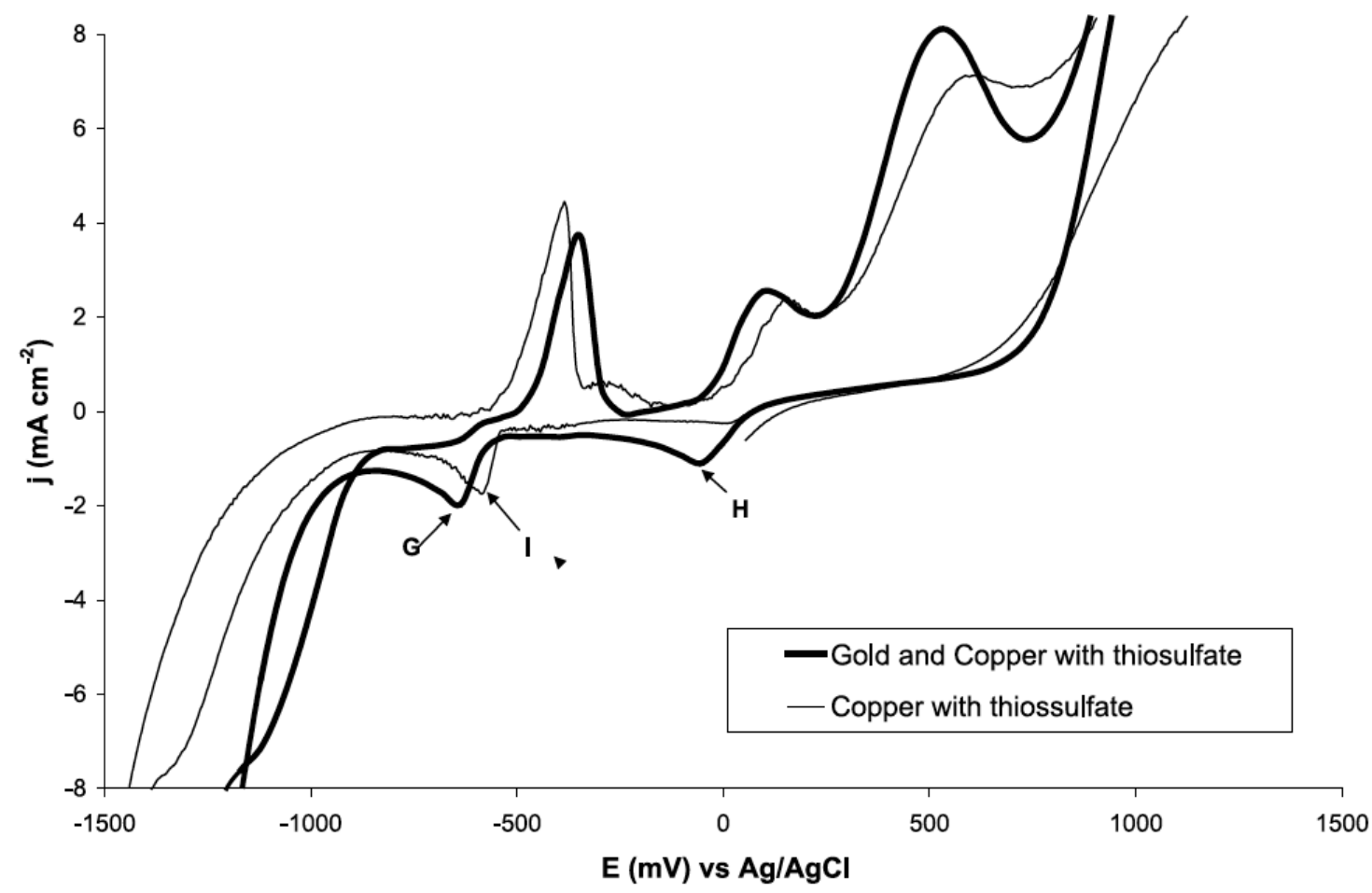

Figure 4. Cyclic voltammograms obtained at a platinum electrode by $500 \mathrm{ppm} \mathrm{Au,} 15$ $\mathrm{mM} \mathrm{CuSO}_{4}, 0.2 \mathrm{M}$ de NH$_{4} \mathrm{OH}$, and $0.12 \mathrm{M} \mathrm{Na}_{2} \mathrm{~S}_{2} \mathrm{O}_{3}$; Scan rate $20 \mathrm{mVs}^{-1}$; without agitation.

\section{Electrolysis studies}

To study the possibility of selective separation of gold in the presence of copper in thiosulphate medium, several electrolysis steps were carried out in the potentiostatic mode, in which the potentials are selected from the results obtained in the voltammetric study, as discussed earlier. Figures 5 and 6 show the evolution of the concentration of gold and copper, respectively, as a function of the time for different electrode potentials applied to a solution containing $100 \mathrm{ppm}$ of gold and $1000 \mathrm{ppm}$ of copper. As shown in Figure 5, the fraction of recovered gold increases with time and is higher than how much more cathodic electrode potential is applied. On the other hand, in Figure 6, it can be seen that copper is deposited only in the potentials that are more cathodic than -700 $\mathrm{mV}$. Therefore, according to the earlier results, it is possible to conduct gold recovery for electrowinning in the presence of copper. 


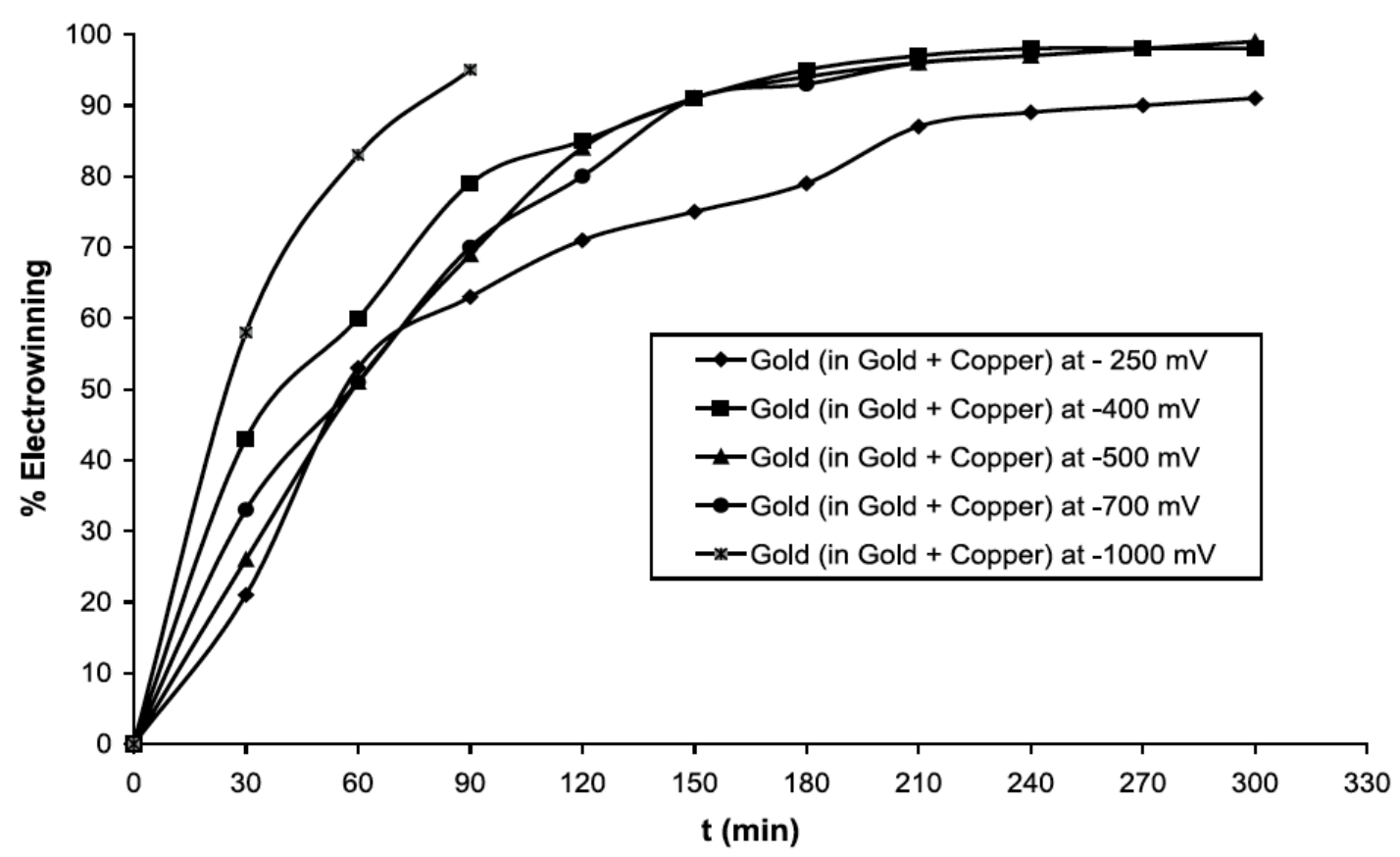

Figure 5. Behaviour of gold during the electrolysis in ammonium medium: for gold 100 ppm and for copper 1000 ppm.

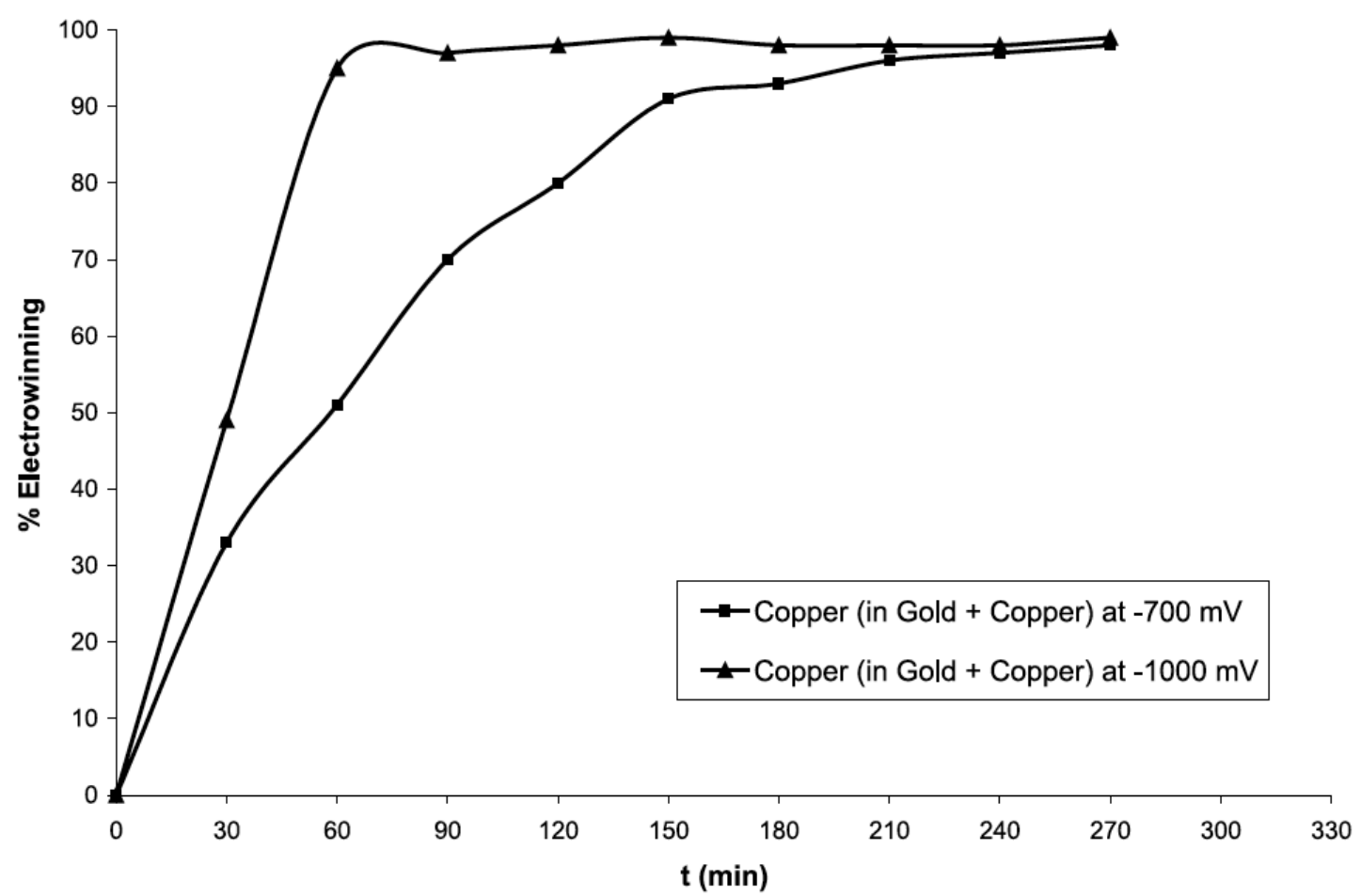

Figure 6. Behaviour of copper during the electrolysis in ammonium medium: for gold $100 \mathrm{ppm}$ and for copper $1000 \mathrm{ppm}$.

In Figure 5, it can be seen that at $-250 \mathrm{mV}$ (vs $\mathrm{Ag} / \mathrm{AgCl}$ ), the rate of gold recovered from the solution from thiosulphate (in ammoniacal medium) containing gold and copper was approximately $90 \%$ in 300 minutes; whereas at $-400 \mathrm{mV},-500 \mathrm{mV}$, and $-700 \mathrm{mV}$ (vs $\mathrm{Ag} / \mathrm{AgCl}$ ), the gold recovered rate was close to $99 \%$ in 300 minutes. Thus, the gold 
electrodeposition should occur in a potential between -400 and $-500 \mathrm{mV}$ (vs $\mathrm{Ag} / \mathrm{AgCl}$ ).

In Figure 6, it can be seen that at cathodic potentials higher than $-1000 \mathrm{mV}$ (vs $\mathrm{Ag} / \mathrm{AgCl}$ ), the rate of the recovery of copper reaches $99 \%$ very rapidly, causing a detachment of the layer deposited at the cathode and consequent redissolution of the copper. However, at $-700 \mathrm{mV}$ (vs $\mathrm{Ag} / \mathrm{AgCl}$ ), the rate of the copper recovery reached $99 \%$ in 270 minutes. In this cathodic potential, the reaction of electrowinning was slower, but the quality of the deposited layer was higher. At a cathodic potential of $-500 \mathrm{mV}$ (vs $\mathrm{Ag} / \mathrm{AgCl}$ ), either no copper was deposited or the rate of electrowinning of copper was below the detection limit.

In Figure 7, the variation of the current with time is shown for each of the applied potentials. As shown, for any of the potentials applied, the current decreases with time owing to the exhaustion of gold and copper ions in the solution. Further, the more negative the potential applied, the greater is the current, because the speed of the electrochemical reactions is greater. The increase of current with the potential for the values of -700 and $-1000 \mathrm{mV}$ should be noted, owing to joint deposition of gold and copper.

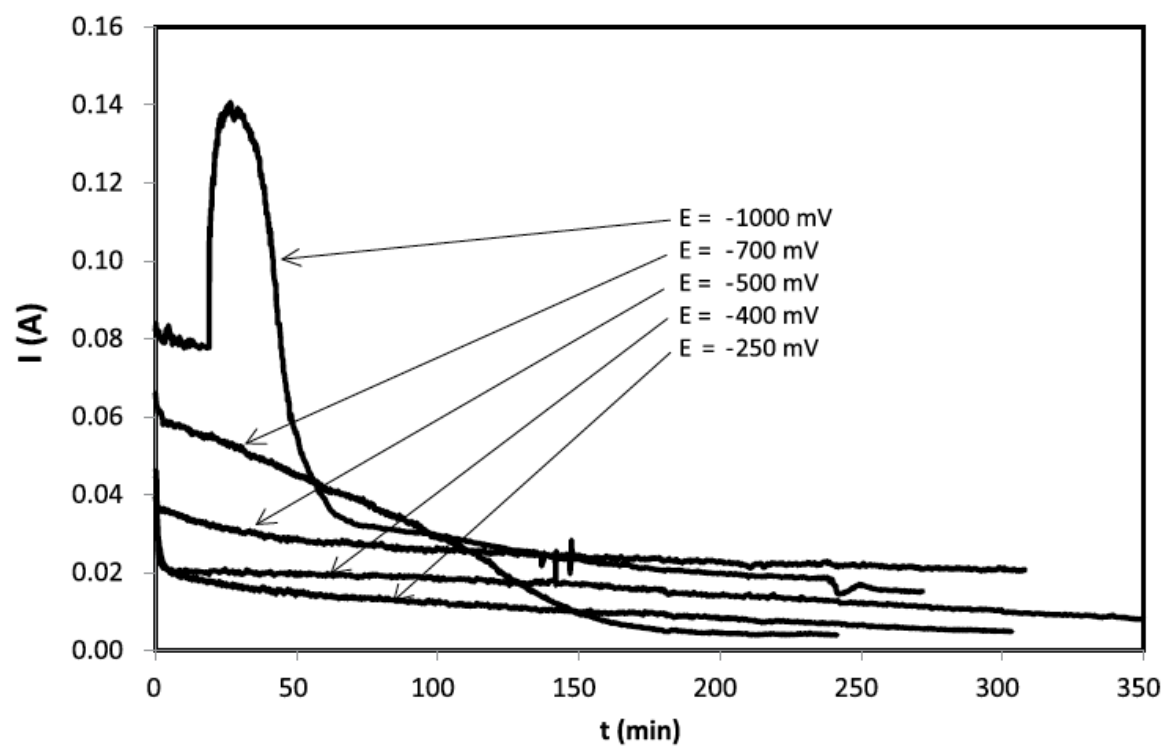

Figure 7. Variation of the current with time for the potential.

For a given value of applied potential, under the conditions that the copper is not deposited, the presence of copper has no influence on the electrochemical deposition of gold, as shown in Figure 8, where it represents the evolution of the concentration of gold with time for an applied potential of $-500 \mathrm{mV}(\mathrm{vs} \mathrm{Ag/AgCl})$. However, the presence of copper influences the intensity for this potential. 


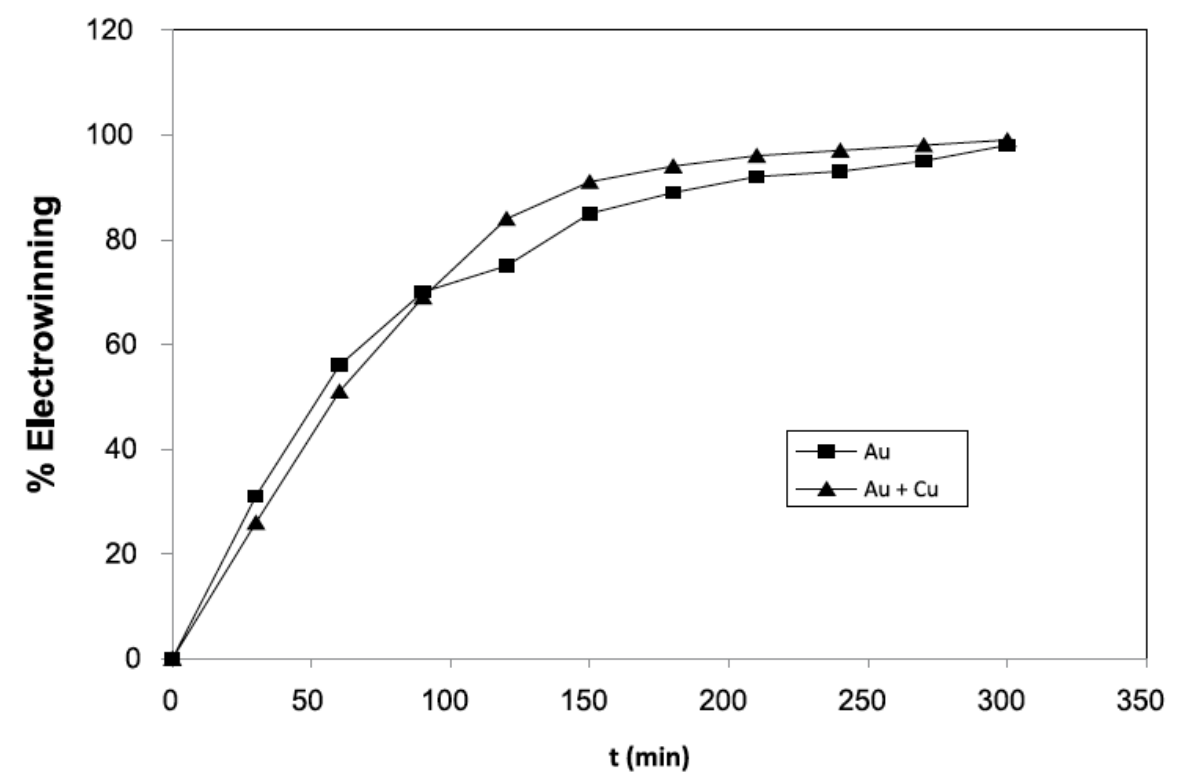

Figure 8. Evolution of the concentration of gold with the time at $-500 \mathrm{mV}$ (vs $\mathrm{Ag} / \mathrm{AgCl})$.

Figure 9 shows the evolution of current over time for a potential of $-500 \mathrm{mV}$ (vs $\mathrm{Ag} / \mathrm{AgCl}$ ). It can be verified that the presence of copper makes the current much higher, probably owing to the copper favouring the hydrogen evolution reaction (Bard and Faulkner, 2001). This results in the electrical performance being much lower in the presence of copper, as shown in Figure 10, where the evolution of the current efficiency is represented by time at a potential of $-500 \mathrm{mV}(\mathrm{vs} \mathrm{Ag/AgCl})$ in the presence and absence of copper in the solution. The current efficiency was calculated by the following expression:

$$
\phi(t)(\%)=\frac{n F\left(C_{0}-C(t)\right) V}{\int_{0}^{t} I(t) \mathrm{d} t} \times 100
$$

where $\phi$ is the current efficiency, $V$ is the reaction volume, $C_{0}$ is the initial gold concentration, $C(t)$ is the gold concentration at time $t, n$ is the number of electrons involved in the electrochemical reaction (1), F is the Faraday's constant, and I is the current.

In Figure 11, the results obtained from tests in a solution with a concentration of gold of $10 \mathrm{ppm}$ can be seen. We can see that for lower gold concentrations, the percentage of gold recovered at $-400 \mathrm{mV}$ (vs $\mathrm{Ag} / \mathrm{AgCl}$ ) was about $60 \%$ in 300 minutes. During the application of the potential of $-500 \mathrm{mV}$, it was possible to recover $90 \%$ of the gold present in the solution. The results suggest that in these cases a potential greater than $-500 \mathrm{mV}$ should be applied (vs $\mathrm{Ag} / \mathrm{AgCl}$ ). 


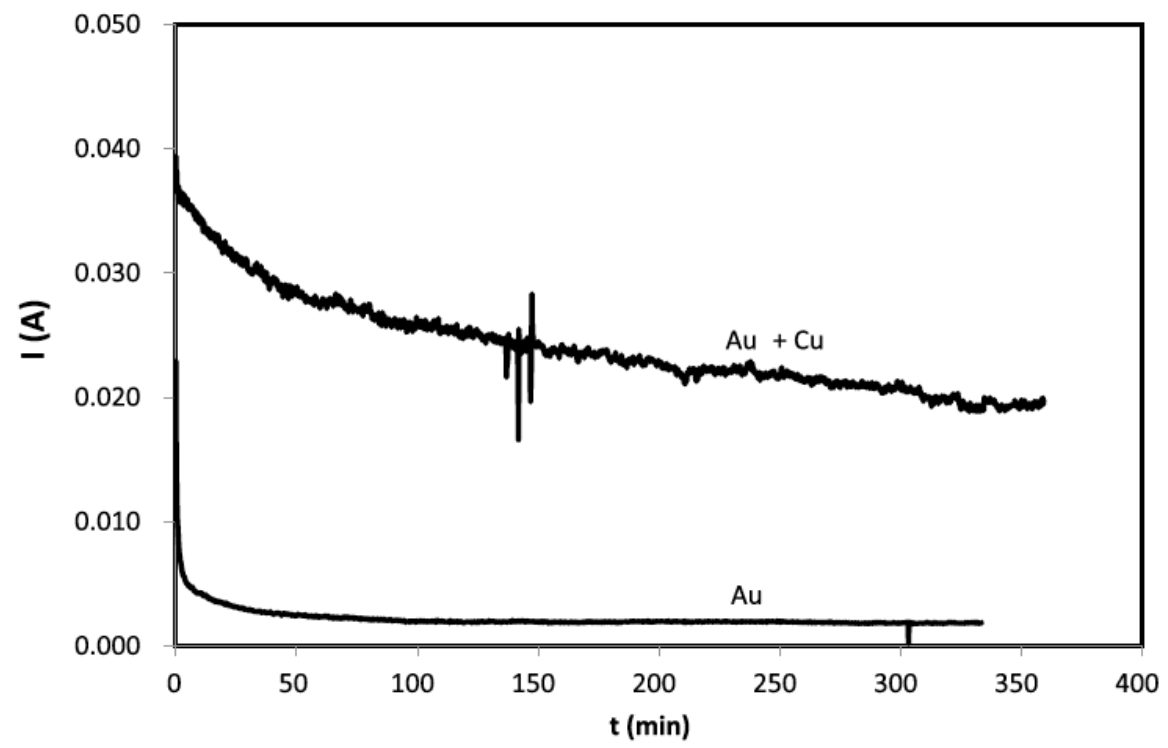

Figure 9. Evolution of current over time at $-500 \mathrm{mV}$ (vs $\mathrm{Ag} / \mathrm{AgCl})$.

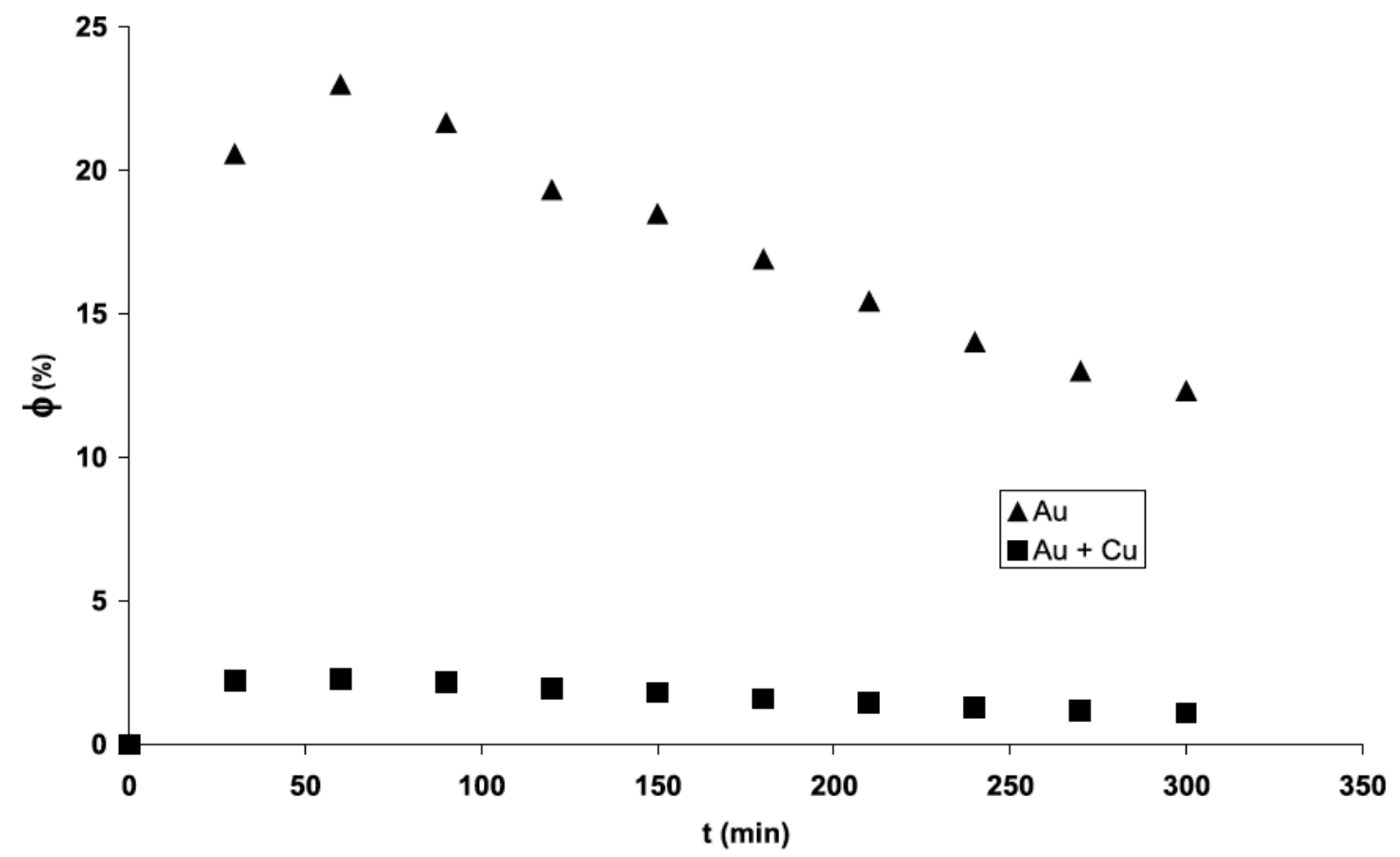

Figure 10. Evolution of the current efficiency with time at a potential of $-500 \mathrm{mV}$ (vs $\mathrm{Ag} / \mathrm{AgCl}$ ). 


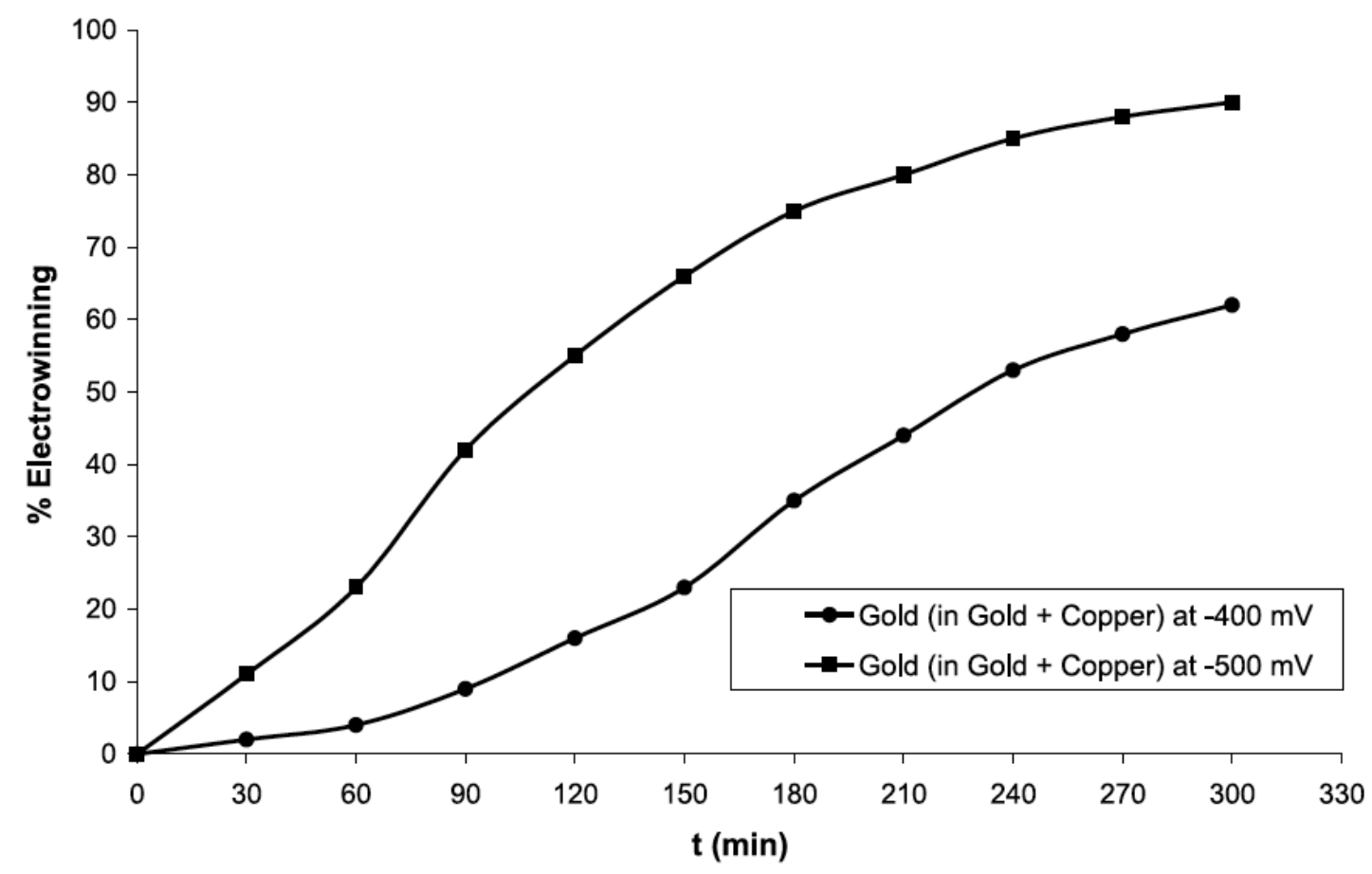

Figure 11. Behaviour of gold during the electrolysis in ammonium medium: for gold 10 ppm and for copper 1000 ppm. 


\section{Conclusions}

The results obtained of this study demonstrate the possibility of a selective recovery of gold and copper from the solutions obtained from the leaching of printed circuit boards, from mobile phones, containing thiosulphate in ammoniacal medium by electrowinning.

The results of the cyclic voltammetry tests show which copper deposition, under these conditions, occurs at potentials more negative than $-600 \mathrm{mV}$ (vs $\mathrm{Ag} / \mathrm{AgCl}$ ), whereas the gold deposition can be performed at potentials more positive than $-600 \mathrm{mV}$ (vs $\mathrm{Ag} / \mathrm{AgCl})$.

The results of the electrodeposition tests show that $99 \%$ of the gold present in solutions containing thiosulphate in ammoniacal medium can be selectively recovered, even in the presence of copper, in a potential range between $-400 \mathrm{mV}$ (vs $\mathrm{Ag} / \mathrm{AgCl}$ ) and -500 $\mathrm{mV}$ (vs $\mathrm{Ag} / \mathrm{AgCl}$ ). A total of $99 \%$ of the copper can be recovered in potentials more negative than $-700 \mathrm{mV}$. 


\section{Acknowledgements}

The authors would like to thank Coordenação de Aperfeiçoamento de Pessoal de Nível Superior (CAPES) and Conselho Nacional de Desenvolvimento Científico e Tecnológico (CNPq) for financial support. 


\section{References}

Abbruzzese C, Fornari P, Massidda R, et al. (1995) Thiosulphate leaching for gold hydrometallurgy. Hydrometallurgy 39: 265-276.

Alonso AR, Lapidus GT and González I (2007) A strategy to determine the potential interval for selective silver electrodeposition from ammoniacal thiosulfate solutions. Hydrometallurgy 85: 144-153.

Arslan F and Sayiner B (2008) Extraction of gold and silver from Turkish gold ore by ammoniacal thiosulphate leaching. Mineral Processing and Extractive Metallurgy Review 29: 68-82.

Aylmore MG (2005) Alternative lixiviants to cyanide for leaching gold ores. Developments in Mineral Processing 15: 501-539.

Aylmore MG and Muir DM (2001) Thiosulfate leaching of gold - A review. Minerals Engineering 14: 135-174.

Babu BR, Parande AK and Basha CA (2007) Electrical and electronic waste: A global environmental problem. Waste Management \& Research 25: 307-318.

Bard AJ and Faulkner LR (2001) Electrochemical Methods - Fundamentals and Applications, 2nd ed. New York: John Wiley.

Berezowsky RMG and Sefton VB (1979) Recovery of gold and silver from oxidation leach residues by ammoniacal thiosulphate leaching. In: $108^{\text {th }}$ AIME annual meeting, New Orleans, Louisiana, USA, 18 February-22 February 1979.

Breuer PL and Jeffrey MI (2000) Thiosulfate leaching kinetics of gold in the presence of copper and ammonia. Minerals Engineering 13: 1071-1081.

Carrillo-Abad J, García-Gabaldón M, Ortega E, et al. (2012) Recovery of zinc from spent pickling solutions using an electrochemical reactor in presence and absence of an anionexchange membrane: Galvanostatic operation. Separation and Purification Technology 98: 366-374.

Chancerel P, Bolland T and Rotter VS (2010) Status of pre-processing of waste electrical and electronic equipment in Germany and its influence on the recovery of gold. Waste Management \& Research 29: 309-317.

Chancerel P, Meskers CEM, Hagelüken C, et al. 2009 Assessment of precious metal flows during preprocessing of waste electrical and electronic equipment. Journal of Industrial Ecology 13: 791-810.

Feng D and Van Deventer JSJ (2006) Ammoniacal thiosulphate leaching of gold in the presence of pyrite. Hydrometallurgy 82: 126-132. 
Feng D and Van Deventer JSJ (2007) Interactions between sulphides and manganese dioxide in thiosulphate leaching of gold ores. Minerals Engineering 20: 533-540.

Fourcade F, Tzedakis T and Bergel A (2003) Electrochemical process for metal recovery from iodized silver derivatives in liquid/solid mixture: Experimental and theoretical approaches. Chemical Engineering Science 58: 3507-3522.

Friege $H$ (2012) Review of material recovery from used electric and electronic equipment-alternative options for resource conservation. Waste Management \& Research 30: 3-16.

Garcia-Gabaldon M, Perez-Herranz V, Garcia-Anton J, et al. (2005) Electrochemical recovery of tin and palladium from the activating solutions of the electroless plating of polymers Potentiostatic operation. Separation and Purification Technology 45: 183191.

Garcia-Gabaldon M, Perez-Herranz V, Garcia-Anton J, et al. (2006) Electrochemical recovery of tin from the activating solutions of the electroless plating of polymers Galvanostatic operation. Separation and Purification Technology 51: 143-149.

Giannopoulou I, Panias D and Paspaliaris I (2009) Electrochemical modeling and study of copper deposition from concentrated ammoniacal sulfate solutions. Hydrometallurgy 99: 58-66.

Gromov OG, Kuz'min AP, Kunshina GB, et al. (2004) Electrochemical recovery of silver from secondary raw materials. Russian Journal of Applied Chemistry 77: 62-66.

Grosse AC, Dicinoski GD, Shaw MJ, et al. (2003) Leaching and recovery of gold using ammoniacal thiosulfate leach liquors (a review). Hydrometallurgy 69: 1-21.

Ha VH, Lee JC, Jeong J, et al. (2010) Thiosulfate leaching of gold from waste mobile phones. Journal of Hazardous Materials 178: 1115-1119.

Hagelüken C and Corti CW (2010) Recycling of gold from electronics: Cost-effective use through 'Design for Recycling'. Gold Bulletin 43: 209-219.

Harrison JA and Thompson J (1973) The electrodeposition of precious metals - A review of the fundamental electrochemistry. Electroochimica Acta 18: 829-834.

Huisman J, Kuehr R, Magalini S, et al. (2007) 2008 Review of Directive 2002/96 on Waste Electrical and Electronic Equipment (WEEE). Bonn: United Nations University.

Jeffrey MI (2001) Kinetic aspects of gold and silver leaching in ammonia-thiosulfate solutions. Hydrometallurgy 60: 7-16.

Kasper AC, Bernardes AM and Veit HM (2011a) Characterization and recovery of polymers from mobile phone scrap. Waste Management \& Research 29: 714-726. 
Kasper AC, Berselli GBT, Freitas BD, et al. (2011b) Printed wiring boards for mobile phones: Characterization and recycling of copper. Waste Management 31: 2536-2545.

Kasper AC, Berselli GBT, Petter PMH, et al. (2012) Extração hidrometalúrgica de ouro proveniente de sucatas de placas de circuito impresso de telefones celulares. In: 20 CBECIMAT - Congresso Brasileiro de Engenharia e Ciência dos Materiais, 2012, Joinville/SC. Anais 20 CBECIMAT.

Koyama K, Tanaka M, Miyasaka Y, et al. (2006) Electrolytic copper deposition from ammoniacal alkaline solution containing $\mathrm{Cu}(\mathrm{I})$. Materials Transactions 47: 2076-2080.

Lack B, Duncan J and Nyokong T (1999) Adsorptive cathodic stripping voltammetric determination of gold(III) in the presence of yeast mannan. Analytica Chimica Acta 385: 393-399.

Li J, Miller JD, Le Vier M, et al. (1995) The ammoniacal thiosulfate system for precious metal recovery. In: Proceedings of XIX international mineral processing congress, vol.4, San Francisco, CA, 22-27 October 1995, p.37.

Mironov IV and Makotchenko EV (2009) The hydrolysis of AuCl-4 and the stability of aquachlorohydroxocomplexes of gold(III) in aqueous solution. Journal of Solution Chemistry 38: 725-737.

Navarro P, Vargas C, Villarroel A, et al. (2002) On the use of ammoniacal/ammonium thiosulphate for gold extraction from a concentrate. Hydrometallurgy 65: 37-42.

Peng C, Liu Y, Bi J, et al. (2011) Recovery of copper and water from copper electroplating wastewater by the combination process of electrolysis and electrodialysis. Journal of Hazardous Materials 189: 814-820.

Reyes Cruz V, Oropeza MT, Gonzalez I, et al. (2002) Electrochemical recovery of silver from cyanide leaching solutions. Journal of Applied Electrochemistry 32: 473-479.

Senanayake G (2004) Analysis of reaction kinetics, speciation and mechanism of gold leaching and thiosulfate oxidation by ammoniacal copper(II) solutions. Hydrometallurgy 75: 55-75.

Senanayake G (2007) Review of rate constants for thiosulphate leaching of gold from ores, concentrates and flat surfaces: Effect of host minerals and $\mathrm{pH}$. Minerals Engineering 20: 1-15.

Trejo G, Gil AF and Gonzalez I (1996) Electrodeposition of gold in ammoniacal medium: Influence of substrate and temperature. Journal of Applied Electrochemistry 26: 12871294.

Trindade RBE and Barbosa Filho O (2002) Extração de Ouro - Princípios, Tecnologia e Meio Ambiente. Rio de Janeiro, CETEM, Centro de Tecnologia Mineral, Ministério da 
Ciência e Tecnologia.

Tripathi A, Kumar M, Sau DC, et al. (2012) Leaching of gold from the waste mobile phone printed circuit boards (PCBs) with ammonium thiosulphate. International Journal of Metallurgical Engineering 1: 17-21.

UNEP (United Nations Environmental Programme) and UNU (United Nations University) (2009) Recycling - From e-waste to resources, Final report. Berlin.

UNEP (International Panel for Sustainable Resource Management, United Nations Environmental Programme) (2013) Metal recycling - opportunities, limits, infrastructure. Paris.

Vazquez-Arenas J, Lazaro I and Cruz R (2007) Electrochemical study of binary and ternary copper complexes in ammonia-chloride médium. Electrochimica Acta 52: 6106-6117.

Veit HM, Bernardes AM, Ferreira JZ, et al. (2006) Recovery of copper from printed circuit boards scraps by mechanical processing and electrometallurgy. Journal of Hazardous Materials B 137: 1704-1709.

Yap CY and Mohamed N (2007) An electrogenerative process for the recovery of gold from cyanide solutions. Chemosphere 67: 1502-1510.

Zhang S and Nicol JM (2003) An electrochemical study of the dissolution of gold in thiosulfate solutions. Part I. Alkaline solutions. Journal of Applied Electrochemistry 33: 767-775.

Zhang S and Nicol JM (2005) An electrochemical study of the dissolution of gold in thiosulfate solutions. Part II. Effect of copper. Journal of Applied Electrochemistry 35: 339-345.

Zhang Y, Liu S, Xie H, et al. (2012) Current status on leaching precious metals from waste printed circuit boards. Procedia Environmental Sciences 16: 560-568. 